\title{
The Competitive Advantage of Developing Offshore Wind Energy in China
}

\author{
Ru Liu, Yanjun Liu and Rong Li \\ No.6 Building, No.11, DongBinHe Rd.Deshengmen, Xicheng District, Beijing, China
}

\begin{abstract}
Compared to onshore wind power, offshore wind power has a relatively short history. The offshore wind potential in China is about 3 times larger than onshore, yet China had not dedicated into offshore wind research and development until recent years. China has the incentive to construct offshore wind farms along its southeast coast. This area is adjacent to China's southeast developed regions where it is highly populated and lacking conventional energy supply. And then, we compare with the cost of offshore wind power and fossil fuel fired generation will show which power generation is more attractive.
\end{abstract}

Keywords-offshore wind power; competitive advantage; economic effect

\section{HISTORY OF OFFSHORE WIND POWER DEVELOPMENT}

Compared to onshore wind power, offshore wind power has a relatively short history. The first offshore wind farm was constructed in Vindeby, Denmark in 1991, with 11 turbines of total capacity of $4.95 \mathrm{MW}$. By the end of 2000, there were in total 30MW offshore wind farms worldwide. In 2002, a wind farm with 80 turbines was built in the North Sea, with a generation capacity of $160 \mathrm{MW}$. By the end of 2005, the world offshore wind farm capacity reached 700MW. By the end of 2007, offshore wind capacity reached 1,080 MW, taking 1.5\% share of total installed capacity. $90 \%$ of the capacity is distributed in European countries such as Denmark and the UK [1]. In that year, China, Norway, Spain, and the USA planned to install their first offshore wind farm within the decade.

Offshore wind power is still very new energy technology everywhere. At the beginning of 1970s, some Europe countries came up with offshore wind power thoughts. During 1991 and 2000, Denmark, Netherlands and Sweden have finished the trial-manufacture of the model machine and gained experience in offshore wind power equipment [4].

Started from 1999, the offshore wind farms had a rapid development. More and more countries started to develop in this energy area. The first commercial offshore wind farm was constructed in Copenhagen Denmark, with 20 turbines each has a capacity of 2 MW. As shown in figure I, there are only 6 offshore wind projects in Europe with a capacity of only 32MW. Until 2007, the industry of Europe had developed 25 projects with a total capacity of about 1232 MW [3]. Most of these offshore wind farms are large-scale and for commercial use. In the year 2008, among the newly added energy capacity in the EU which was $23,851 \mathrm{MW}$, wind power took the largest share of $36 \%$. It was the first time in Europe that wind power dominated the energy structure. [2]

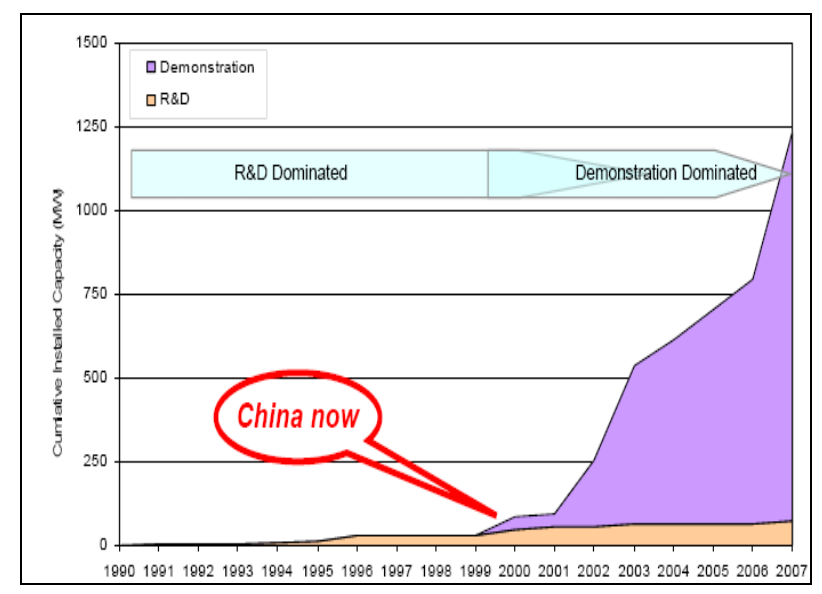

FIGURE I. EUROPE OFFSHORE WIND POWER DEVELOPMENT

[3].

Offshore wind in Europe has been developed rapidly during the last decade, installed capacity increased from $32 \mathrm{MW}$ in 1999 to 1,232 MW in 2007. China's offshore wind power development is at the bottom level over the world. About 10-15 GW of installed capacity in Europe can be forecast. Drivers of offshore wind farms are different from country to country. The development of offshore wind power is driven by rich wind resources, experience from onshore wind development, good economic management, and governmental policy.

\section{OFFSHORE WIND POWER FOREGROUND IN CHINA}

The offshore wind potential in China is about 3 times larger than onshore, yet China had not dedicated into offshore wind research and development until recent years. China has the incentive to construct offshore wind farms along its southeast coast. This area is adjacent to China's southeast developed regions where it is highly populated and lacking conventional energy supply. The first commercial offshore wind turbine in China was installed on East China Sea March 20, 2009. It belongs to Shanghai East China Sea offshore Wind Project which will install 34 wind-driven generators along the Shanghai East China Sea Bridge, each with a capacity of 3 MW. The total installed capacity will be $102 \mathrm{MW}$ [5].

Zhe jiang province is in short of energy. Most of its energy depends on neighboring provinces. So Zhe Jiang province makes a policy with exploring offshore wind resource as its key point for its renewable energy development plan [5]. 
2010, China has already sketched out six offshore wind power plans along the east coastline in all: Bohai Suizhong(1.5MW), Hebei(50MW), Dongshan Island(20MW), Nan'ao(20MW), Qingdao(20MW), and Shanghai Donghai Bridge offshore wind farm (100MW). Among them, Bohai Suizhong project is a demonstration project with only one turbine and has been in operation since 2007. Shanghai offshore wind farm is the only project in the East China Sea area and this project is the largest offshore wind project in China. Figure II shows the allocation of planned offshore wind farms in China.

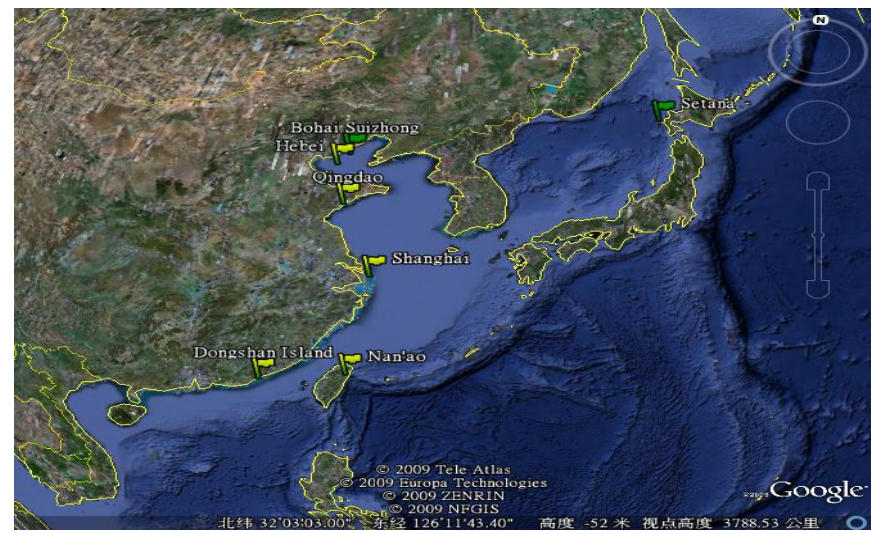

FIGURE II. THE CHINESE OFFSHORE WIND POWER MAPPED BY OFFSHORE CENTER DENMARK

Shanghai Donghai Bridge offshore wind farm is the largest commercial offshore wind farm among the 6 planned projects. The Bohai Suizhong wind project is a demonstration project with only one turbine with a capacity of $1.5 \mathrm{MW}$. The other 5 are to be constructed in the near future.

Up to date, China's total wind turbine installed capacity will hit 100 million KW by 2015, including 5 million KW on offshore. Wind power has become the third largest electric power in China. China is determined to promote the revolution of energy generation and consumption, to control the total consumption of energy, to improve energy conservation, and to support the development of energy conservation and low carbon industry as well as renewable energy in order to ensure the national energy safety.

Unfortunately, the development of offshore wind energy does not come as fast as expected. In May 2014, China had only installed about 565MW offshore wind capacity, still far from the target goal of 5 gigawatts (GW) by the end of 2015 and 30GW by 2020 .

\section{COMPARE WITH OFFSHORE WIND POWER AND FOSSIL FUEL FIRED GENERATION}

As a largely untapped energy resource, offshore wind power in China is one of the key projects to address the climate goals and energy demands with lower environmental impact and lower social risk. It will be one of important components in renewable energy resource structure.

Offshore wind power in China is clearly a viable energy power in future. Along with the trend with fuel costs on the rise, any renewable power (like natural gas) with free fuel costs becomes economically viable. And what's more, the coal fire power plant also plays a very important role in China electricity market. To compare with the cost of offshore wind power and fossil fuel fired generation will show which power generation is more attractive.

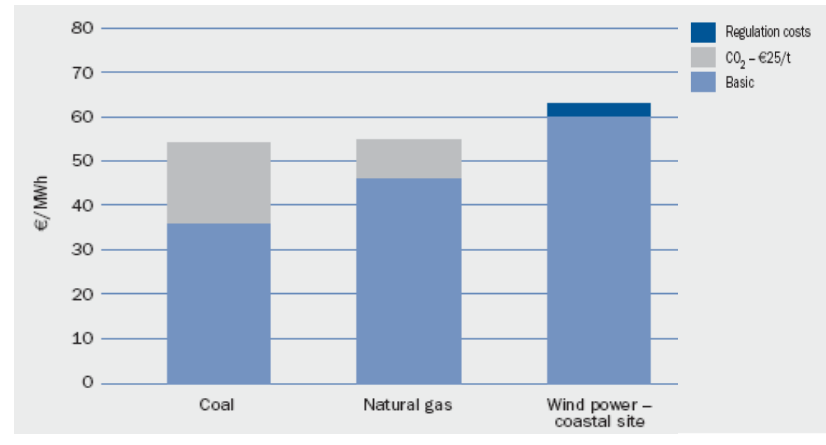

FIGURE III. COST OF ENERGY COMPARISON WITH FOSSIL FUEL FIRED GENERATION IN 2009[6].

As shown in figure III, the wind power has the higher capital costs, but there is no fuel cost. It is not an attractive investment compare with coal fired power plant and natural gas power plant in short term. The coal and natural gas power plant produce GHG emission into atmosphere from the environmental aspect. They can not to avoid GHG emission cost. Because the energy shortage of the world and the heavy demand for CO2 sent the price up in future, a sensitivity analysis is carried as shown in following figure IV.

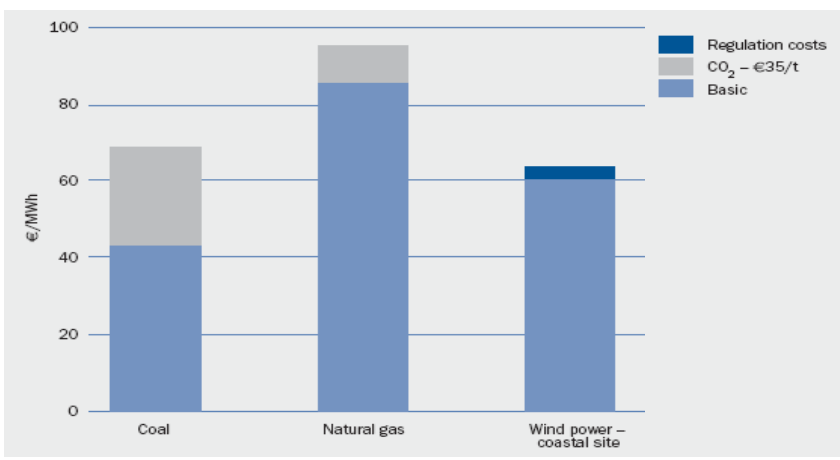

FIGURE IV. COST OF ENERGY COMPARISON WITH FOSSIL FUEL FIRED GENERATION IN FUTURE[6]

The natural gas price has rapid increase compared to high oil price in future. And the coal price also increase to 70 Euro per MWh from 55 Euro per MWh in 2009. Thus, offshore wind power is very close to being competitive with rising fuel and carbon prices, not only comparison with onshore farm, but also in comparison with other traditional power stations. Even offshore wind energy is more expensive per KWh, it has a significant attraction compare other fossil fuel fired generation, because it decrease the investment risk and hedges against unexpected rises in cost of oil and $\mathrm{CO} 2$ in the future. 


\section{KEY RECOMMENDATIOINS FOR ACTION}

According to China' s Wind Power Development Roadmap 2050, which issued by the energy research institute of National Development and Reform Commission, until 2021, China will focus on onshore wind development. Overall, China plans to have 1,000 gigawatts (GW) of installed wind capacity by 2050, making up 17 percent of the country's electricity consumption. China's offshore wind farm in commercial operation will play a very important role in this target. But some offshore wind power are facing a number of technical and commercial barriers in moving forward at the rate required to meet the Government targets. Barriers include uncertainty over an effective and efficient long-term pricing policy that is needed by project developers while ensuring consumers are protected from high costs, a slow consenting regime and the lack of a focused innovation programme to drive costs out of the deployment process.

In order to speed up China's offshore programme and help ensure China government targets are met in a cost effective way. China should consider follow recommendations:

- Develop an offshore wind capital grants scheme;

- Support R\&D and technology testing of offshore wind power;

- Develop an effective publicly funded research and demonstration programme;

- Develop an effective on-going price support mechanism to balance developer incentives with government costs.

China faces numerous challenges to the development of the offshore wind industry. But given the rapid growth of the onshore market, there can be confidence that China can achieve its offshore wind targets, perhaps not by 2020, but perhaps by 2050.

\section{REFERENCES}

[1] Dan Rigden, Todd Westbrook, Offshore wind: will it deliver? http://www.energyinst.org.uk/content/files/danrigden.pdf accessed on 06.10.14.

[2] EWEA, 2009, http://www.ewea.org/index.php?id=1338

[3] Garrad Hassan and Partners Ltd, 2009, International Experience and Practice in Offshore Wind Farm Development

[4] Hu Qiying, 2005, Development status of offshore wind energy technology in Europe

[5] Offshore Wind China 2009 Conference, 2009.10.10 http://www.offshorewindchina.cn/english/ accessed on 07.10.09

[6] Soren Krohn, 2009, The Economics of Wind Energy, page13, 49, 69, a report by the European Wind Energy Association. 